\title{
Structural impact damage of metal honeycomb sandwich plates
}

\author{
Qinghua Qin ${ }^{\text {a,b,c }}$, Shangjun Chen ${ }^{\text {a,d }}$, Kaikai Li $^{\text {a }}$, Minqiang Jiang ${ }^{\text {e, Tianning Cui }}{ }^{\text {a }}$, Jianxun Zhang ${ }^{\text {a,e,* }}$ \\ a State Key Laboratory for Strength and Vibration of Mechanical Structures, Department of Engineering Mechanics, Xi'an Jiaotong University, Xi'an 710049, China \\ ${ }^{\mathrm{b}}$ Science and Technology on Transient Impact Laboratory, No. 208 Research Institute of China Ordnance Industries, Beijing 102202, China \\ ${ }^{\mathrm{c}}$ State Key Laboratory of Explosion Science and Technology, Beijing Institute of Technology, Beijing 100081, China \\ d Xi'an Thermal Power Research Institute Co., Ltd, Xi'an 710054, China \\ ${ }^{\mathrm{e}}$ State Key Laboratory of Nonlinear Mechanics, Institute of Mechanics, Chinese Academy of Sciences, Beijing 100190, China
}

\section{A R T I C L E I N F O}

\section{Keywords:}

Metal honeycomb sandwich plate

Low-velocity impact

Dynamic response

Dynamic failure

Energy absorption

\begin{abstract}
A B S T R A C T
Dynamic response of sandwich plates with a metal honeycomb core under low-velocity impact has been investigated. Experiments of the fully clamped sandwich plates subjected to low-velocity impact of the drop-hammer with a hemispherical nose have been conducted and plastic failure modes have been measured. Structural damage mechanism of sandwich plates has been identified and explored. It is found that finite element simulations of these experiments are in good agreement with the experimental measurements. Analytical solutions for permanent deflections and peak impact forces are derived and capture the experimental results with reasonable accuracy. It is shown that the impact positions have important influence on the dynamic response of sandwich plates subjected to low-velocity impact. The impact resistance of sandwich plate decreases from the central position to the non-central positions.
\end{abstract}

\section{Introduction}

Metal honeycomb sandwich structure has been widely used in engineering because of its lightweight and multifunctional characteristics. During its service, it often suffers from low-velocity impact load, which has a high randomness, that is, the impact position is uncertain, and the impact energy is uncertain. Thus, it is important to study the dynamic response of metal honeycomb sandwich plates under lowvelocity impact at non-center impact position.

Over the past decades, analytical investigations were devoted to the low velocity impacts of sandwich structures. For example, Foo et al. [1] proposed a modified energy-balance model coupled with the law of conservation of momentum to predict the dynamic response of sandwich plates under low-velocity impact. Plagianakos and Papadopoulos [2] analytically predicted the global and through-thickness local dynamic response of pristine simply-supported cross-ply composite and sandwich composite plates with piezoelectric sensory layers subjected to low-energy impact. Fard et al. [3] analytically studied the low velocity impact of a composite sandwich plate impacted by a rigid blunted cylinder, and the results show that the stacking sequence of the face sheet has an insignificant effect on both the impact force and the contact duration. Mohammadi et al. [4] analyti- cally studied the low velocity impact response on sandwich plates with functionally graded face sheets based on high-order sandwich plate theory, and the model is also checked by finite element simulation for validation. Arachchige and Ghasemnejad [5] developed an extensive analytical model to determine behaviour of curved sandwich plates with variable stiffness cores and face-sheets under low velocity impact, and numerical analysis was performed to validate with the analytical models. Qin and Wang [6] developed an analytical model to predict the dynamic response of fully clamped square sandwich plates with metal foam core struck transversely by a heavy mass with low-velocity.

In addition, the experimental and numerical methods are used to study the low-velocity impact of sandwich structures. Herup and Palazotto [7] conducted low-velocity impact tests on sandwich plates composed of 4- to 48-ply graphite/epoxy cross-ply laminate face sheets and Nomex honeycomb cores to characterize damage initiation as a function of face sheet thickness and loading rate. Crupi and Montanini [8] carried out static and dynamic three-point bending tests to investigate the structural response of two different typologies of aluminium foam sandwich panels, and simplified theoretical collapse models were introduced to explain the observed experimental behaviour, showing good agreement between analytical

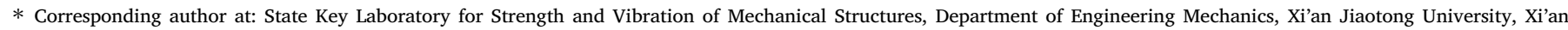
710049, China.

E-mail address: jianxunzhang@mail.xjtu.edu.cn (J. Zhang).
} 
and experimental results. Yu et al. [9] carried out the quasi-static and low-velocity impact bending tests to explore the response and failure of sandwich beams with aluminum-foam core. Rajaneesh et al. [10] numerically studied the low-velocity impact on openface sandwich plates using an impactor, and it is found that the simulated force versus time, and energy absorbed versus time responses along with the predicted failure modes and analytically predicted peak loads are in good agreement with that of the experimental results. Ivañez et al. [11] experimentally studied low-velocity oblique impact on composite sandwich plates, and found that maximum contact force decreases with increasing impact angles, whereas it increases with impact energy until a certain value in which remains almost constant. Kurşun et al. [12] carried out experimental and numerical analysis to study the influence of impactor shapes on the low velocity impact performance of aluminium sandwich composite plates. Abo Sabah and Kueh [13] numerically investigated the effect of localized interface progressive delamination on the behavior of two-layer laminated composite plates subjected to low velocity impact loading for various fiber orientations. Liu et al. [14] numerically studied the dynamic mechanical responses of aluminum honeycomb sandwich structures to study the effects of different impact velocities, honeycomb side length and wall thickness on the stress, strain and displacement of structures. Chen et al. [15] numerically studied damage behaviours of composite sandwich structures with a honeycomb core subjected to low-velocity perforation impact. Park [16] numerically investigated low-velocity impact behaviors of monolithic laminate plate and sandwich composite plate, and it is found that the sandwich plate has less displacement than the composite laminate composed of only ply materials in the low-velocity impact.

As mentioned above, a wealth of literature is mostly focused on the dynamic response of the sandwich structures under low-velocity impact at the central position, while little attention is paid on the effect of impact position on structural damage of sandwich structures. In this study, we employ the drop-hammer system to explore the dynamic response of metal honeycomb sandwich plates under lowvelocity impact considering the effect of impact positions. Firstly, the manufacturing route of metal honeycomb sandwich plates is detailed and the experimental procedure is described for loading the sandwich plates by the drop-hammer with a hemispherical nose. Next, the finite element simulations are conducted to determine dynamic failure mechanism. Finally, the finite element simulations and theoretical predictions are compared with the experimental results and the influence of various parameters is studied.

\section{Experimental}

\subsection{Specimen configuration and manufacture}

The top and bottom face sheets of metal honeycomb core sandwich plates are made of AL-2024 with the thickness $h_{f}=0.7 \mathrm{~mm}$; The honeycomb core is made of AL-5052 foil with the thickness $h_{c}=0.05 \mathrm{~mm}$. Circumscribed circle diameter of the honeycomb cell is $D=4.76 \mathrm{~mm}$, the height of the core is $c=5 \mathrm{~mm}$, as shown in Fig. 1 . The honeycomb is made by hot pressing and stretching according to adhesive method. The quasi-static tensile and compressive tests are carried out for the face sheet and honeycomb core. The material properties are listed in Tables 1 and 2.

In the preparation of metal honeycomb sandwich plate, the edge of honeycomb core material needs to be filled with Styrofoam. Due to the high compressive strength of the cured styrofoam, it can prevent the core from crushing during the experiment. The plate and the honeycomb core are bonded together through the adhesive film under high temperature and high pressure. The size of the specimen is $L \times L=320 \mathrm{~mm} \times 320 \mathrm{~mm}$, the total thickness of the sandwich plate is $2 h_{f}+c=6.4 \mathrm{~mm}$ (The adhesive film thickness is neglected after hot pressing). The sandwich plate and the clamped plate are fixed with M12 bolts, the experimental area is $L^{\prime} \times L^{\prime}=276 \mathrm{~mm} \times 276 \mathrm{~mm}$, as shown in Fig. 2.

\subsection{Test protocol}

Three typical impact positions are selected: impact point $\mathrm{P} 1$ at the center, impact point $\mathrm{P} 2$ at $1 / 4$ of the median line, and impact point $\mathrm{P} 3$ at $1 / 4$ of the diagonal line of the sandwich plates, as shown in Fig. 3. The initial impact energy of the hammer head is determined by setting the height of the hammer head for the given weights of the hammer head and counterweight, as listed in Table 3.12 specimens are manufactured to test and divided into 3 cases.

\subsection{Experimental setup}

Impact tests were conducted on the drop-hammer impact systems (DHR-1205), as shown in Fig. 4(a). Load cell and laser displacement sensor are used to record the time history of impact force and displacement of hammer head. The impact forces were measured by DEWE high speed data system.

The setup consists of four parts: upper and lower splints, support plate and test-bed. In the experiment, the boundary condition of the

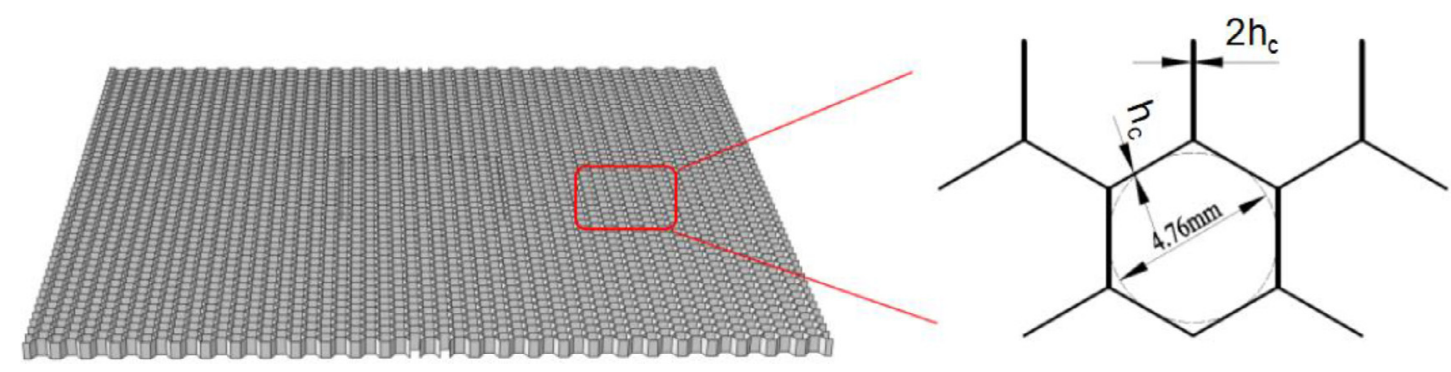

Fig. 1. Geometry of aluminum honeycomb.

Table 1

Material parameters of face sheets and matrix material of honeycomb.

\begin{tabular}{|c|c|c|c|c|}
\hline Material & Density $/ \mathrm{kg} / \mathrm{m}^{3}$ & Elastic Modulus/GPa & Poisson's ratio & Yield strength/MPa \\
\hline $\mathrm{Al}-2024$ & 2770 & 70 & 0.33 & 251 \\
\hline Al-5052-foil & 2770 & 70 & 0.33 & 275 \\
\hline
\end{tabular}


Table 2

Properties of honeycomb core.

\begin{tabular}{llll}
\hline $\begin{array}{l}\text { Density/ } \\
\mathrm{kg} \mathrm{m}^{-3}\end{array}$ & $\begin{array}{l}\text { Yield strength/ } \\
\mathrm{MPa}\end{array}$ & $\begin{array}{l}\text { Platform stress/ } \\
\mathrm{MPa}\end{array}$ & $\begin{array}{l}\text { Densification } \\
\text { strain }\end{array}$ \\
\hline 70.4 & 4.82 & 2.20 & 0.81 \\
\hline
\end{tabular}

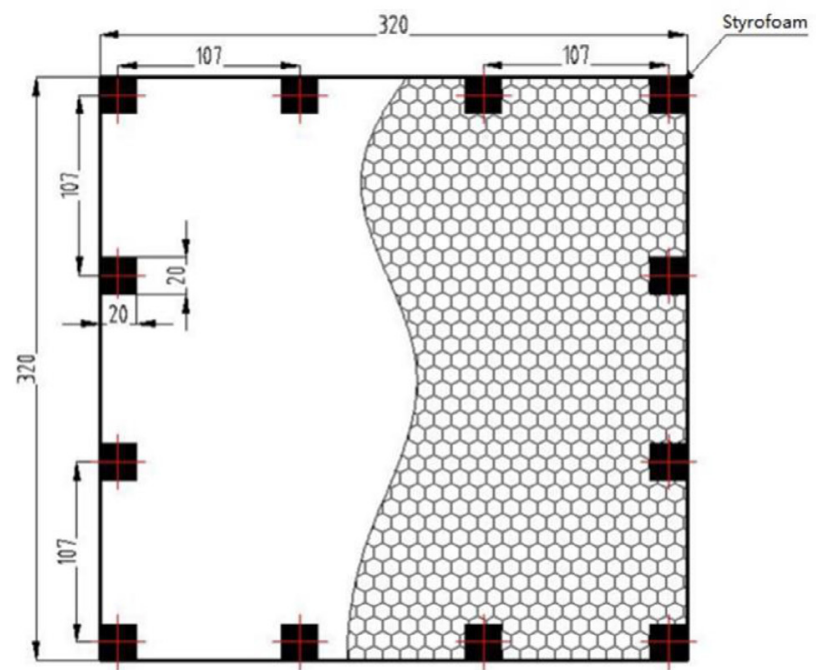

(a)

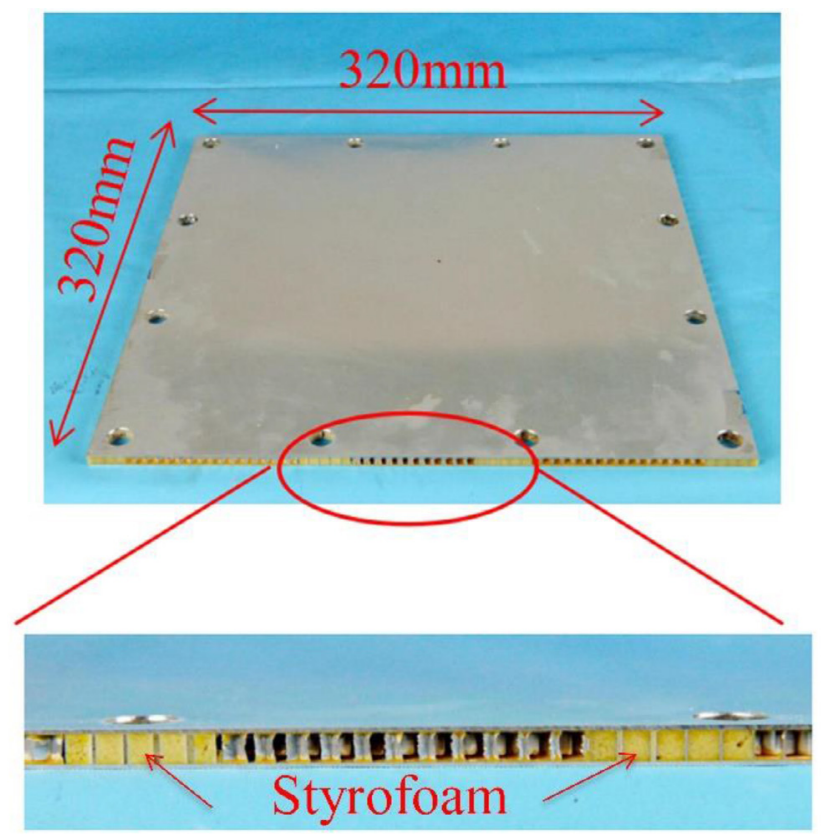

(b)

Fig. 2. Sandwich plate specimen. (a) Geometry, and (b) cross-section.

specimen is fully clamped by bolts at four sides, as shown in Fig. 4(b). The hammer spherical head of diameter $R=40 \mathrm{~mm}$ is made of the Cr12MoV steel. The total mass of hammer head, counterweight and

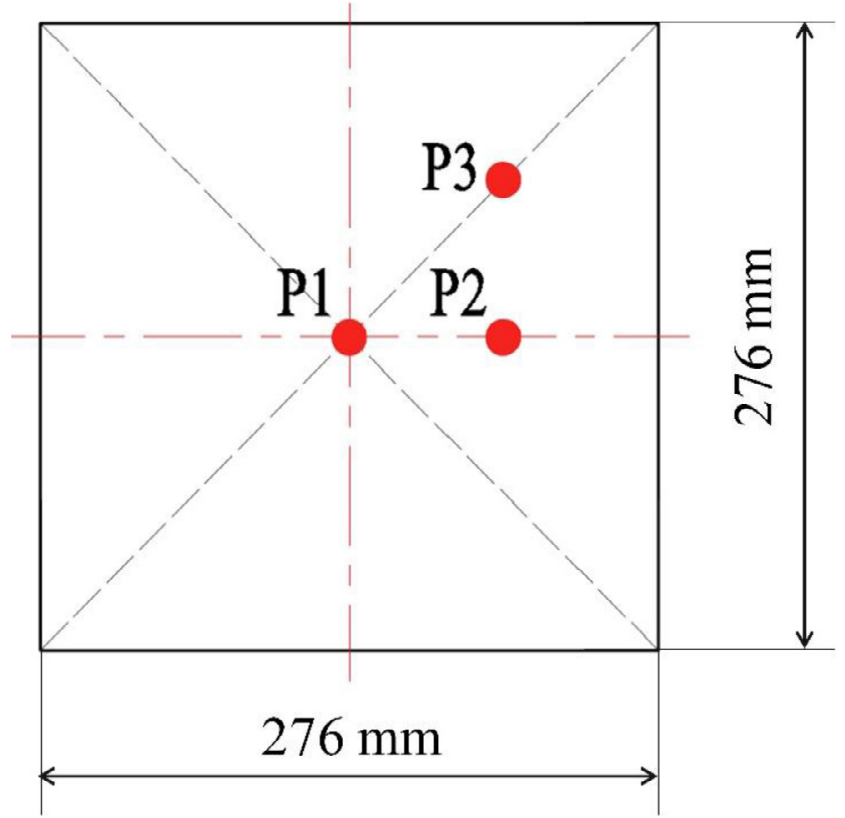

Fig. 3. Three impact positions of sandwich plate specimen.

Table 3

Details of experiments.

\begin{tabular}{llllll}
\hline \multicolumn{4}{l}{ Mass $G=34.45 \mathrm{~kg}$} & & \\
\hline $\begin{array}{l}\text { Impact } \\
\text { Position }\end{array}$ & $V_{0}$ & $\begin{array}{l}\text { Impact } \\
\text { Position }\end{array}$ & $V_{0}$ & $\begin{array}{l}\text { Impact } \\
\text { Position }\end{array}$ & $V_{0}$ \\
\hline P1 & $1.5 \mathrm{~m} / \mathrm{s}$ & P2 & $1.5 \mathrm{~m} / \mathrm{s}$ & P3 & $1.5 \mathrm{~m} / \mathrm{s}$ \\
P1 & $2.3 \mathrm{~m} / \mathrm{s}$ & P2 & $2.0 \mathrm{~m} / \mathrm{s}$ & P3 & $2.3 \mathrm{~m} / \mathrm{s}$ \\
P1 & $2.5 \mathrm{~m} / \mathrm{s}$ & P2 & $2.3 \mathrm{~m} / \mathrm{s}$ & P3 & $2.5 \mathrm{~m} / \mathrm{s}$ \\
P1 & $4.0 \mathrm{~m} / \mathrm{s}$ & P2 & $4.0 \mathrm{~m} / \mathrm{s}$ & P3 & $4.0 \mathrm{~m} / \mathrm{s}$ \\
\hline
\end{tabular}

release device is $G=34.45 \mathrm{~kg}$. The diameter of the spherical hammer head is $d=25 \mathrm{~mm}$ (Spherical radius $R=40 \mathrm{~mm}$ ), as shown in Fig. 4(c).

\section{Finite element simulations}

Using the commercial software ABAQUS/Explicit (Version 6.13) commercial software, the dynamic response of the clamped metal honeycomb sandwich plate under low-velocity impact is modelled numerically. The hammer is modeled by a rigid body with a concentrated mass, and the initial velocity of the hammer is defined by a predefined field. The numerical models of the metal honeycomb sandwich plates under the low-velocity impact have a same geometry to the experimental specimens. Herein, the aluminum alloy was modelled by employing Johnson-Cook rate-dependent hardening model [17] and the damage law.

$\bar{\sigma}=\left[A+B\left(\bar{\varepsilon}_{p l}\right)^{n}\right]\left[1+C \ln \left(\frac{\dot{\bar{\varepsilon}}_{p l}}{\dot{\varepsilon}_{0}}\right)\right]\left[1-\left(\frac{T-T_{T}}{T_{M}-T_{T}}\right)^{m}\right]$

where $\bar{\sigma}$ is the equivalent stress, $\bar{\varepsilon}_{p l}$ is the equivalent plastic strain, $n$ is a strain hardening index, $\underset{p l}{\dot{\varepsilon}}$ is the equivalent plastic strain rate, $\dot{\varepsilon}_{0}$ is the reference strain rate, $T_{M}$ and $T_{T}$ are the melting and transitive temperatures respectively and $A, B, C$ and $m$ are material constants.

The Johnson-Cook damage law was employed to model failure of the aluminum alloy. This model is then given by the following form 


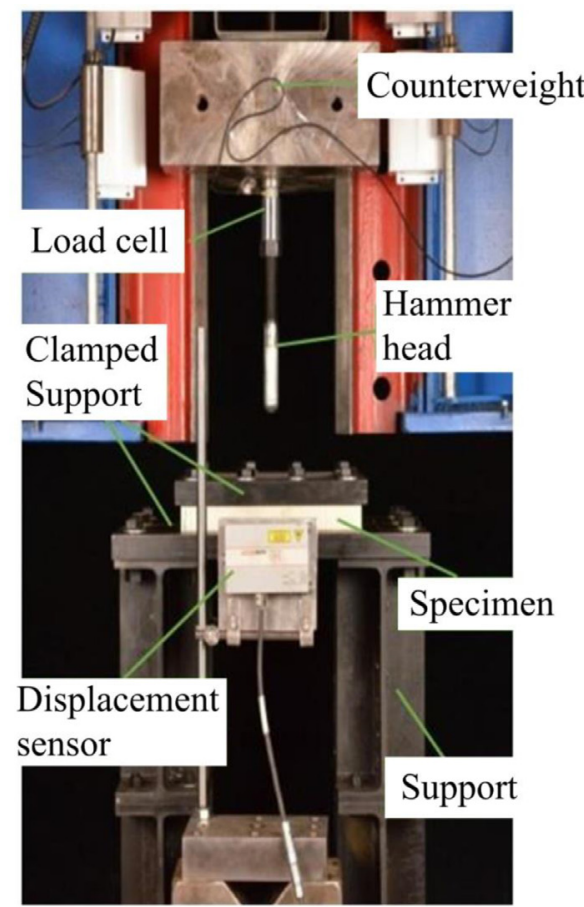

(a)

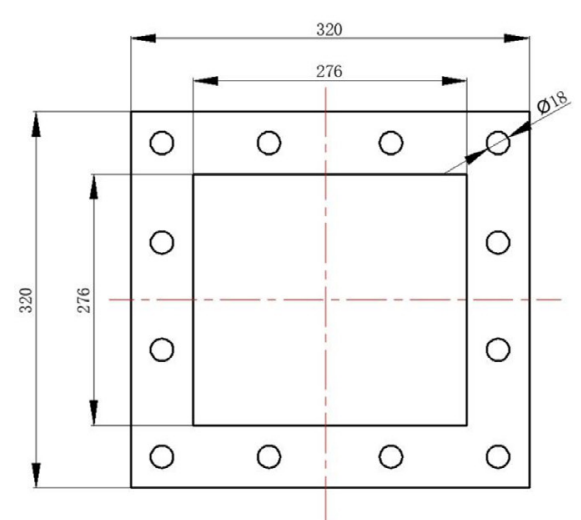

(c)

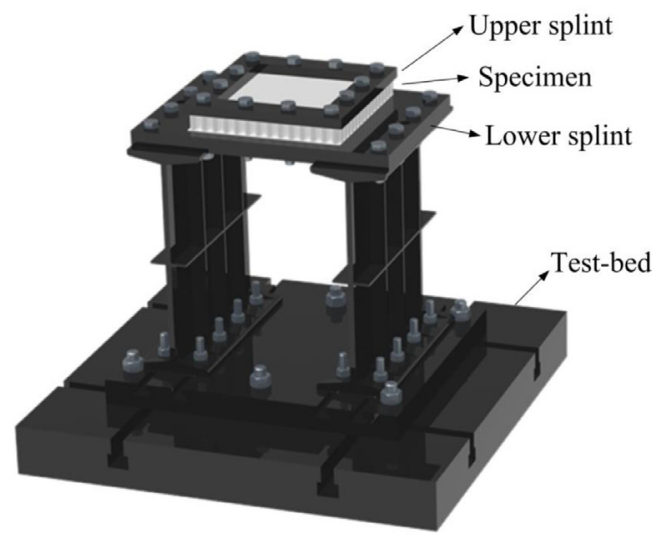

(b)

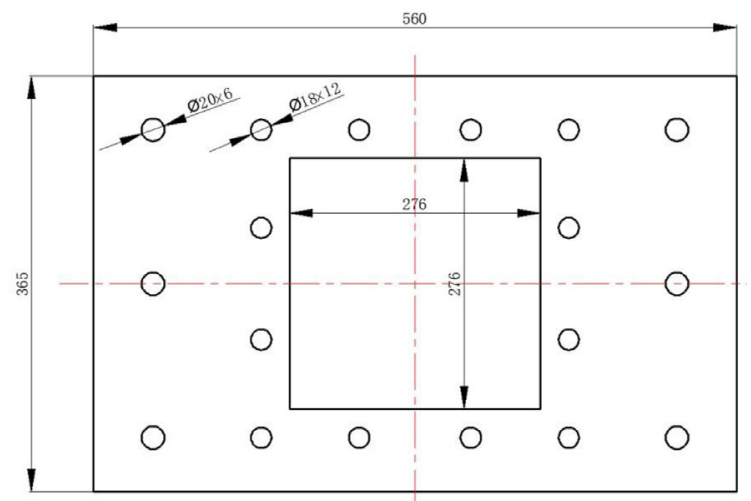

(d)

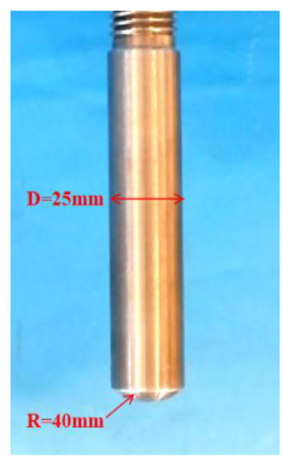

(e)

Fig. 4. Experimental setup. (a) The drop-hammer impact system, (b) fully clamped jig, (c) upper splint (mm), (d) lower splint (mm), and (e) hammer head. 
Table 4

Johnson-Cook parameters of face sheets and honeycomb core.

\begin{tabular}{|c|c|c|c|c|c|c|c|c|c|c|c|c|}
\hline Materials & $\begin{array}{l}\mathrm{A} \\
\mathrm{MPa}\end{array}$ & $\begin{array}{l}\text { B } \\
\mathrm{MPa}\end{array}$ & $\mathrm{n}$ & $\mathrm{m}$ & $\begin{array}{l}\mathrm{T}_{\mathrm{M}} \\
\mathrm{K}\end{array}$ & $\begin{array}{l}\mathrm{T}_{\mathrm{T}} \\
\mathrm{K}\end{array}$ & $\mathrm{D}_{1}$ & $\mathrm{D}_{2}$ & $\mathrm{D}_{3}$ & $\mathrm{D}_{4}$ & $\mathrm{D}_{5}$ & $\begin{array}{l}\dot{\varepsilon}_{0} \\
1 / \mathrm{s}\end{array}$ \\
\hline AL2024 & 251 & 200 & 0.5 & 1.0 & 893 & 293 & 0.116 & 0.211 & -2.172 & 0.012 & 0 & $1.11 \mathrm{E}-3$ \\
\hline AL5052-foil & 275 & 180 & 0.37 & 1.0 & 893 & 293 & 0.13 & 0.13 & -1.5 & 0.011 & 0 & $4.17 \mathrm{E}-4$ \\
\hline
\end{tabular}

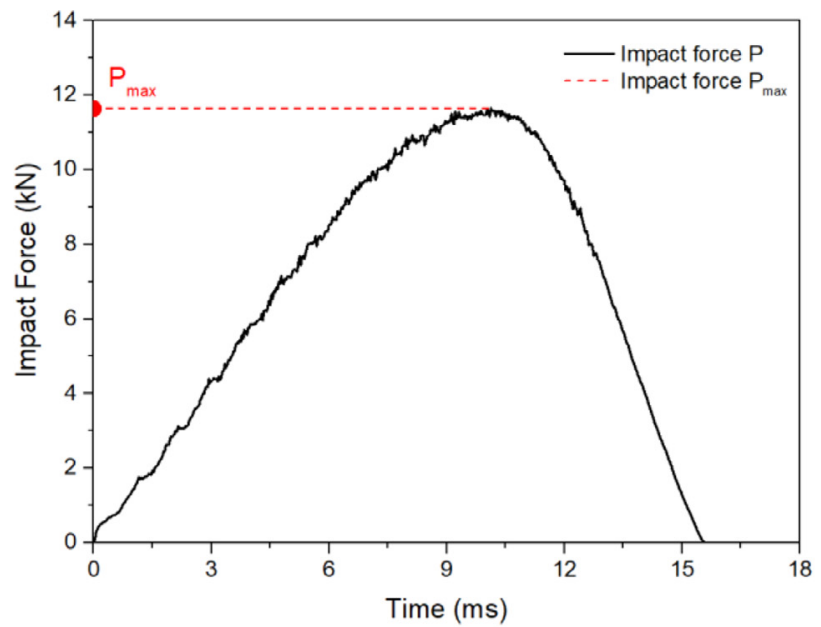

(a)

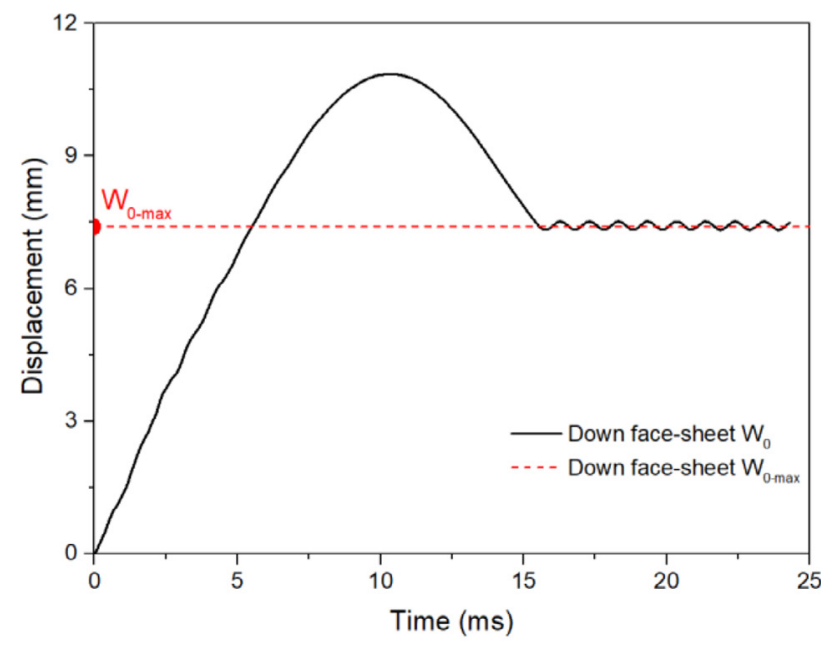

(b)

Fig. 5. Peak value of the impact force and permanent deflection of the bottom face sheet in the center point. (a) The impact force-time curve, and (b) deflection-time curve.

${ }^{-p l}=\left[D_{1}+D_{2} \exp \left(-D_{3} \frac{p}{\bar{\sigma}}\right)\right]\left[1+D_{4} \ln \left(\frac{\dot{\dot{\varepsilon}_{p l}}}{\dot{\varepsilon}_{0}}\right)\right]\left[1+D_{5}\left(\frac{T-T_{T}}{T_{M}-T_{T}}\right)\right]$

where $\varepsilon_{D}^{p l}$ is the equivalent strain to fracture at the current conditions of strain rate, temperature, pressure and equivalent stress, $p$ is a pressure stress, $D_{1}-D_{5}$ are damage parameters. The parameters $A, B$ and $n$ are

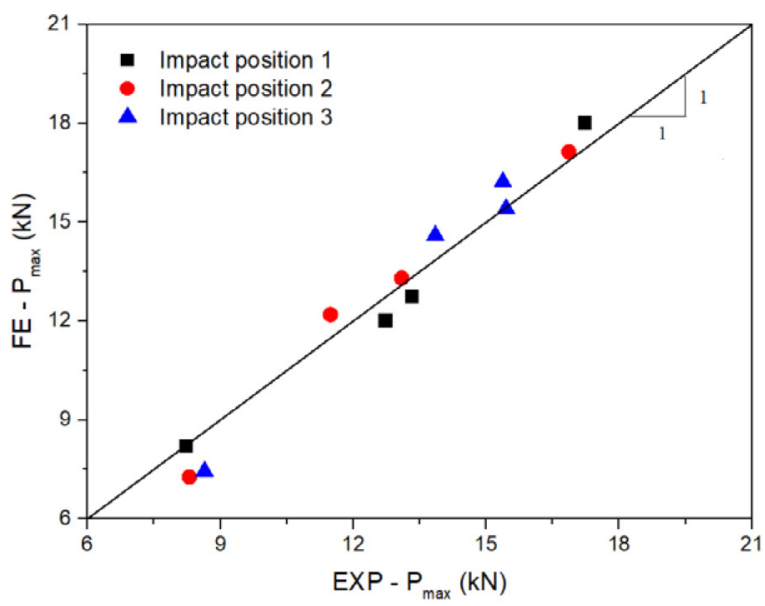

(a)

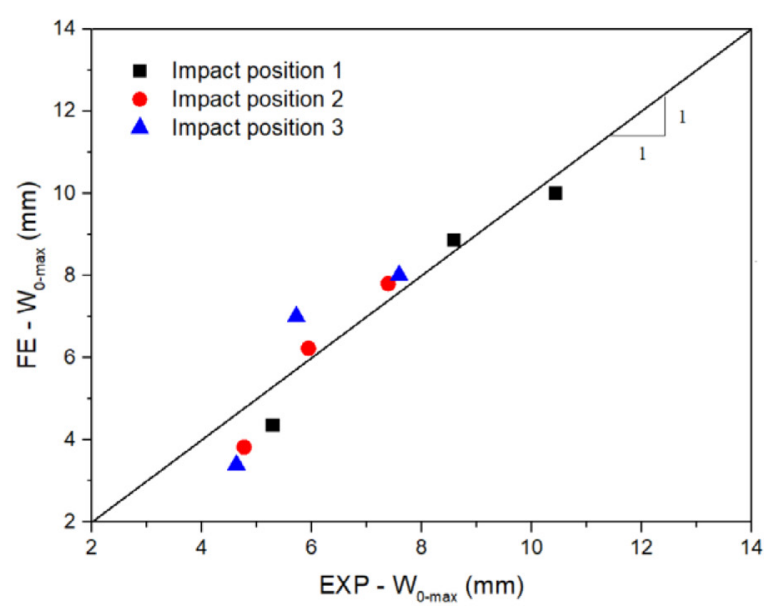

(b)

Fig. 6. Comparisons between experimental and numerical results for (a) the peak values of the impact force, and (b) maximum deflections of the bottom face sheet of the sandwich plates.

defined by fitting the experimental tensile stress-strain relationship of the aluminum alloy. Johnson-Cook parameters are listed in Table 4.

The fully clamped boundary conditions are modelled by setting all the displacements of each node on the boundary of the sandwich plate as zero. The hammer is assumed to only move along the out-of-plane direction of the sandwich plate. The general contact algorithm is adopted in the model and effect of the friction is neglected. The perfect bonding between the top, bottom face sheets and core is modelled by setting "tie" constraint between the face sheet and core. Four-node shell element (S4R) is used to mesh the face sheets and honeycomb core. Mesh refinements have been performed at the contact zone 


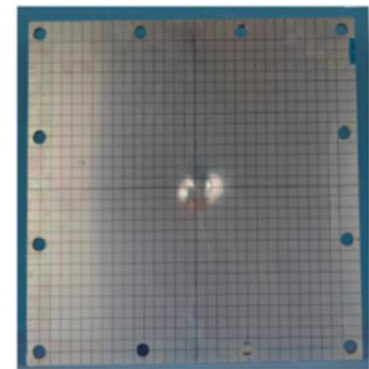

EXP

(a)

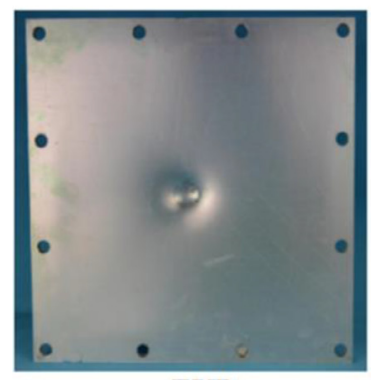

EXP

(b)
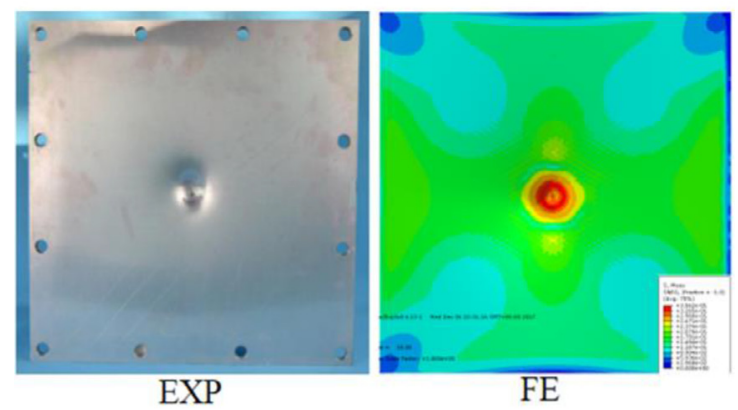

(c)

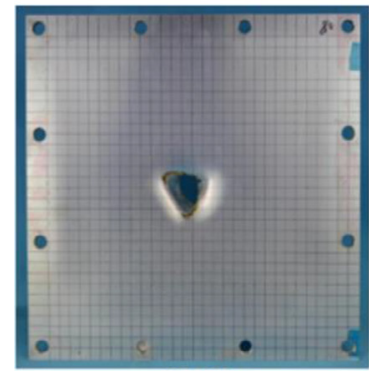

EXP

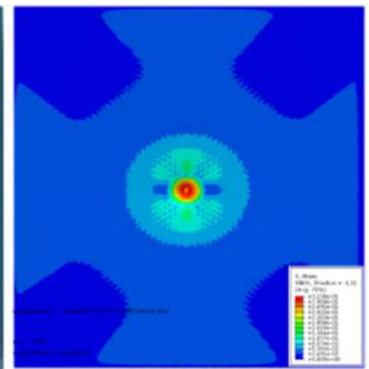

FE
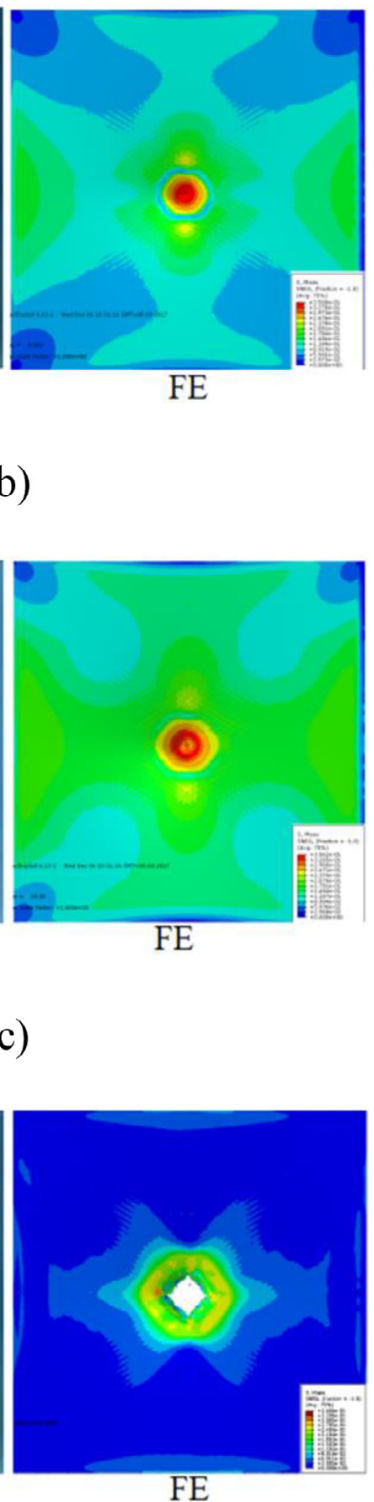

(d)

Fig. 7. Deformation and failure modes of the top face sheets of sandwich plates at impact position P1. (a) $V_{0}=1.5 \mathrm{~m} / \mathrm{s}, E_{\text {inp }}=39 \mathrm{~J}$, (b) $V_{0}=2.3 \mathrm{~m} / \mathrm{s}$, $E_{\text {inp }}=91 \mathrm{~J}$, (c) $V_{0}=2.5 \mathrm{~m} / \mathrm{s}, E_{\text {inp }}=108 \mathrm{~J}$ and (d) $V_{0}=4 \mathrm{~m} / \mathrm{s}, E_{\text {inp }}=276 \mathrm{~J}$.

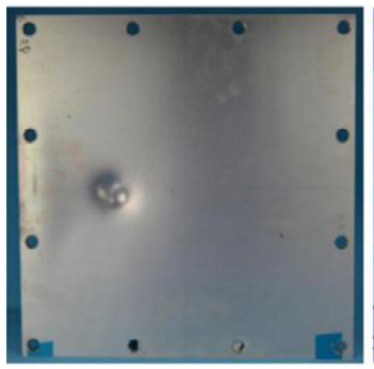

EXP

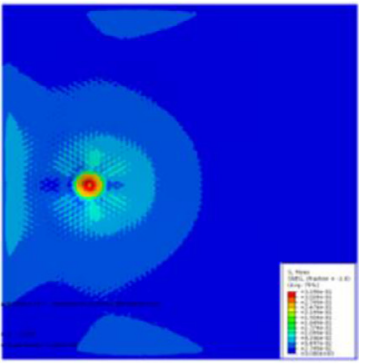

FE (a)

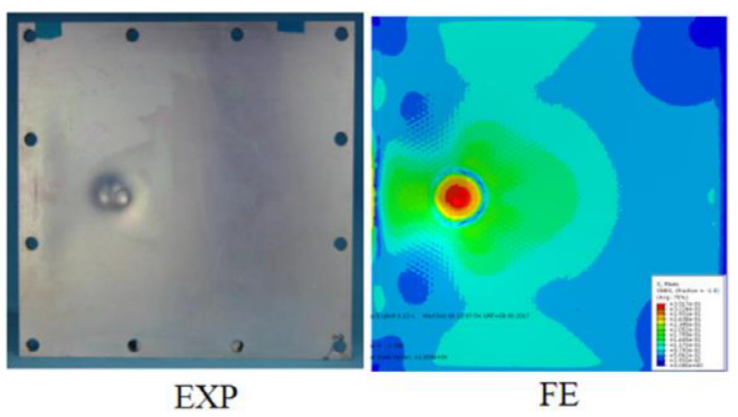

(b)

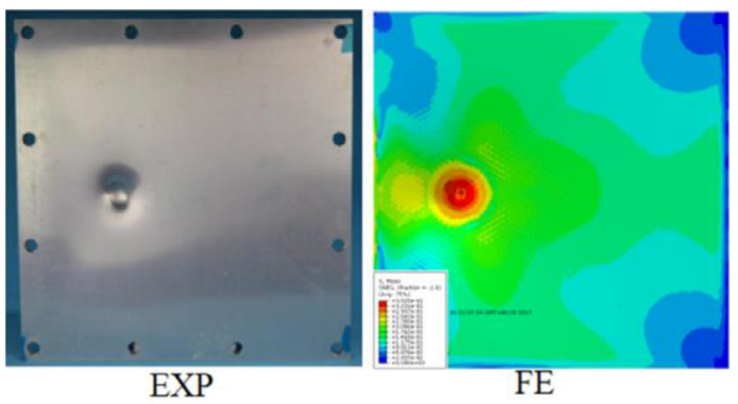

(c)

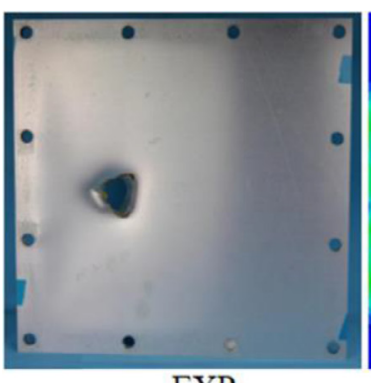

EXP

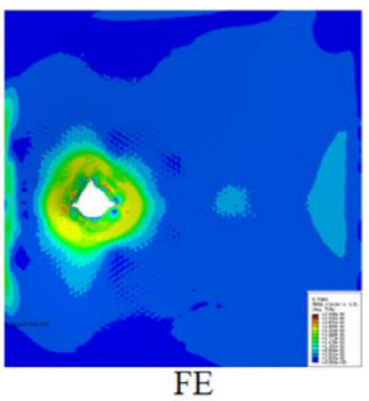

(d)
Fig. 8. Deformation and failure modes of the top face sheets of sandwich plates at impact position P2. (a) $V_{0}=1.5 \mathrm{~m} / \mathrm{s}, E_{\text {inp }}=39 \mathrm{~J}$, (b) $V_{0}=2.0 \mathrm{~m} / \mathrm{s}$, $E_{\text {inp }}=69 \mathrm{~J}$, (c) $V_{0}=2.3 \mathrm{~m} / \mathrm{s}, E_{\text {inp }}=91 \mathrm{~J}$ and (d) $V_{0}=4 \mathrm{~m} / \mathrm{s}, E_{\text {inp }}=276 \mathrm{~J}$. 
between the sandwich plate and the hammer head. The mesh sensitivity has been checked and it is shown that further mesh refinement cannot improve the accuracy of the finite element simulations.

\section{Results and discussion}

\subsection{Comparison of numerical results with experimental results}

Fig. 5 shows a set of typical impact force-time curve and deflectiontime curve at the center of the bottom face sheet. The maximum value of the impact force-time curve is defined as the peak impact force $P_{\max }$. The average value of the oscillating part of the deflection-time curve at the center of the bottom face sheet is defined as the maximum permanent deflection $W_{0-\text { max }}$ of the bottom face sheet. It should be noted that the impact deflection-time curve at the center of the bottom face sheet decreases obviously after attaining the peak value. Finally, it reaches stability. This may be due to the elastic springback of sandwich plate in the unloading process of hammer head rebounded.

Fig. 6 shows comparisons between experimental and numerical results for the peak value of the impact force and the maximum permanent deflection of the bottom face sheet. It is seen that both the numerical results for peak impact force and the maximum permanent deflection of the sandwich plate are in good agreement with the experimental results.

\subsection{Deformation and failure modes}

Figs. 7-9 show the deformation and failure modes of the top face sheets of sandwich plates at impact position P1, P2, and P3 under different impact energy. It is seen that the numerical deformation modes are in good agreement with the experiments. When the impact energy is lower, the top face sheet of the sandwich plate mainly shows the local denting, as shown in Figs. 7(a), 8(a), and 9(a). When the impact energy is higher, the top face sheet of the sandwich plate mainly shows the local denting and overall deformation, as shown in Figs. 7(b), (c), 8 (b), (c), 9(b), and (c). In Fig. 7(b) and (c), there are plastic hinge lines at the fixed boundary. At the boundary near the impact position, a plastic hinge line is formed. However, there are no obvious plastic hinge lines formed near the other boundaries, as shown in Figs. 8 (a)-(c), 9(a)-(c). The depth of local denting also increases with the increase of impact energy. With the increase of impact energy, the local deformations of the top face sheets increase until the face sheet is perforated, as shown in Fig. 7(d), 8(d) and 9(d).

Fig. 10 shows cross-sections of deformation and failure modes of the core in sandwich plates at impact positions P1, P2 and P3. The sandwich plates are cut along the center lines for impact positions P1, P2 and diagonal line for impact position P3, and then are put together for the same specimens under different impact energy. In Fig. 10(a), the core under the hammer head is collapsed by folding. Moreover, shear deformation of the core were observed during the bending process. The shear deformation zone increases with increasing impact energy. There is no obvious deformation observed between the shear deformation zone and the clamped ends of the core. The deformation mode of the sandwich plate is symmetrical at the center impact position. For higher impact energy, the sandwich plate is perforated by petal mode. In Fig. 10(b) and (c), the core under the hammer head is collapsed by folding also. Due to the unsymmetrical impact loadings, it can be found that only there are shear deformation zones at one side.

Figs. 11-13 show the deformation and failure modes of the bottom face sheets of sandwich plates at impact position P1, P2 and P3, respectively. For lower impact energy, the bottom face sheets of sandwich plates deforms plastically, as shown in Fig. 11(a), 12(a) and 13(a). The plastic hinge lines of sandwich plates at impact position P1 are not very obvious, as show in Fig. 11(a). The local deformation of the

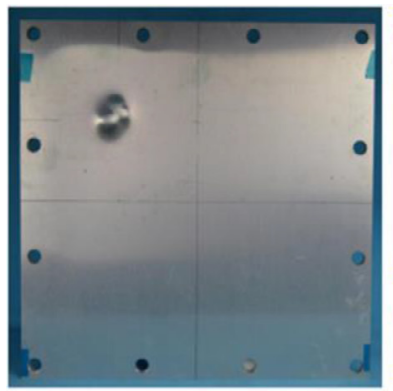

EXP

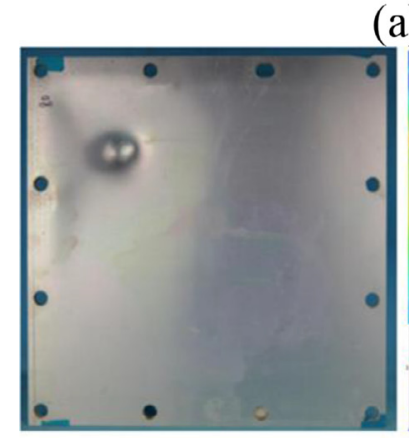

EXP

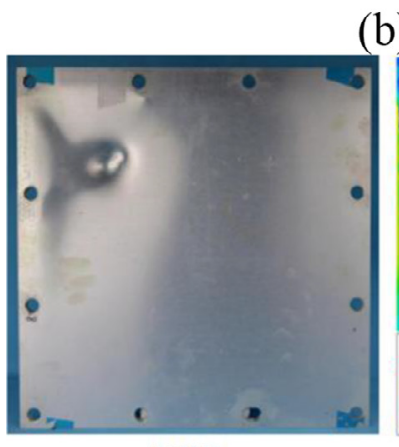

EXP

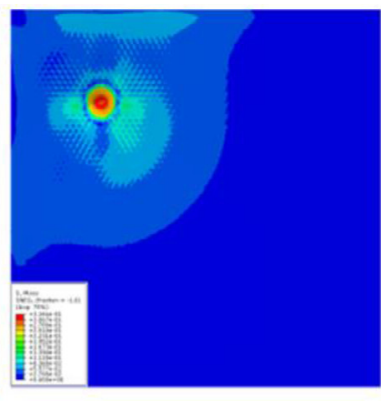

$\mathrm{FE}$ (a)

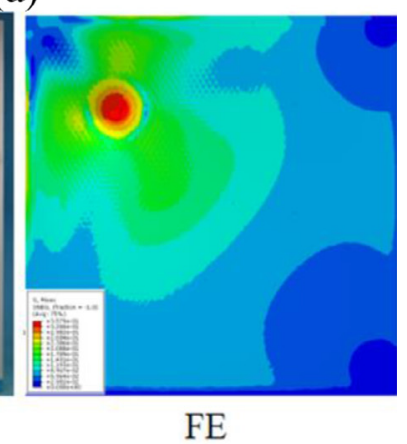

(b)

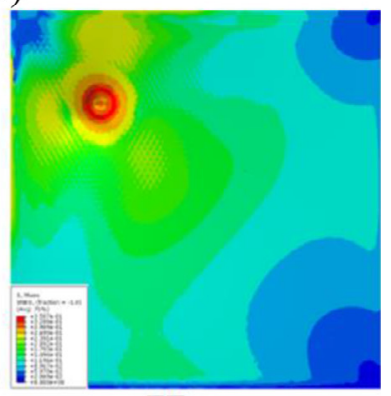

FE

(c)

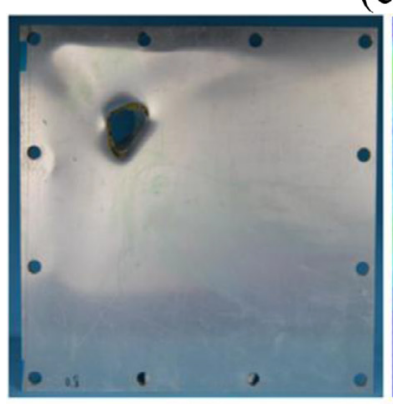

EXP

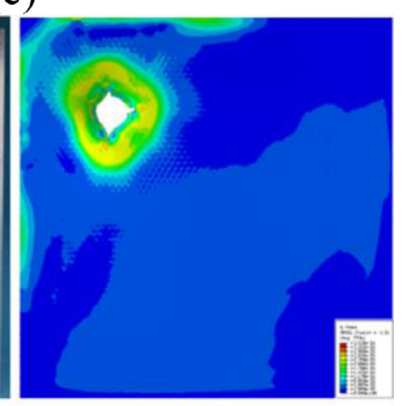

FE (d)

Fig. 9. Deformation and failure modes of the top face sheets of sandwich plates at impact position P3. (a) $V_{0}=1.5 \mathrm{~m} / \mathrm{s}, E_{\text {inp }}=39 \mathrm{~J}$, (b) $V_{0}=2.3 \mathrm{~m} / \mathrm{s}$, $E_{\text {inp }}=91 \mathrm{~J}$, (c) $V_{0}=2.5 \mathrm{~m} / \mathrm{s}, E_{\text {inp }}=108 \mathrm{~J}$ and (d) $V_{0}=4 \mathrm{~m} / \mathrm{s}, E_{\text {inp }}=276 \mathrm{~J}$. 


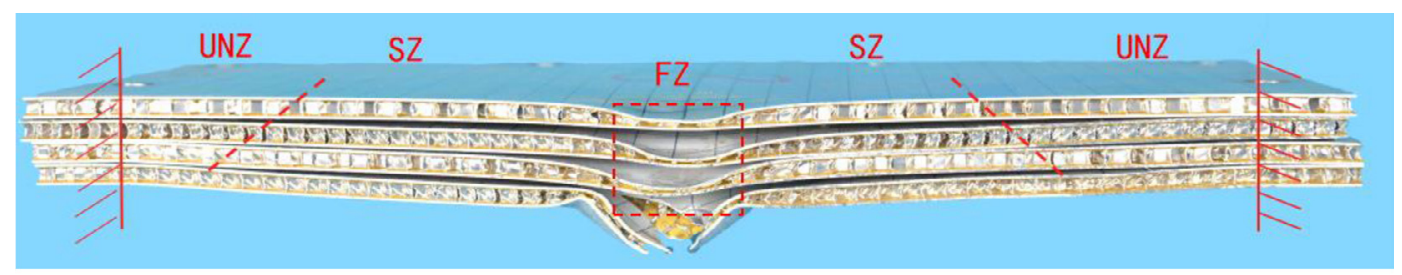

(a)

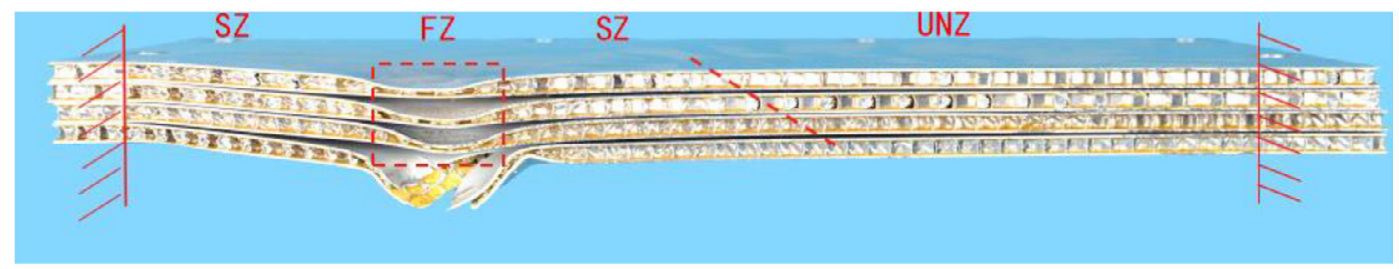

(b)

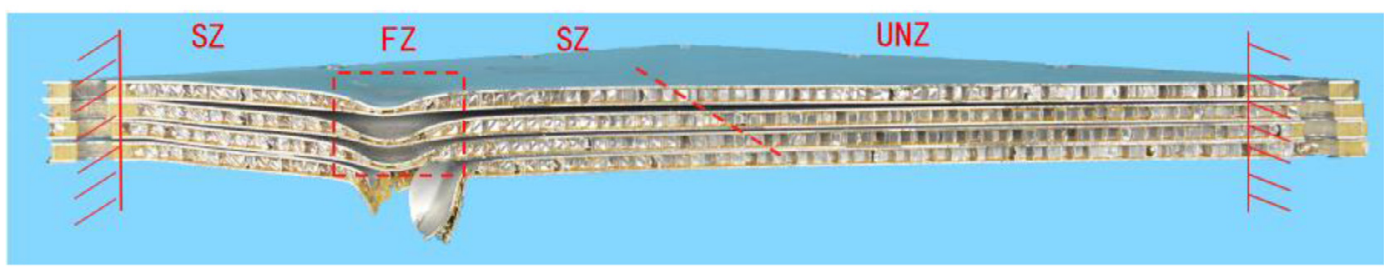

(c)

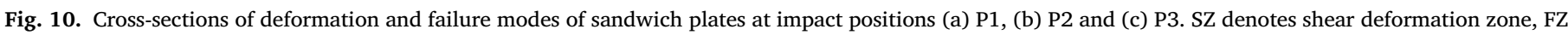
denotes folded deformation zone, UNZ denotes undeformation zone. Oblique lines denote shear deformation zone.

bottom face sheet becomes larger with the increase of impact energy, and the plastic hinge lines were formed, as show in Fig. 11(b)-(d). The plastic hinge line at the boundary near the impact position was also found while no obvious deformation was observed at the three boundary areas far away from the impact position, as show in Fig. 12(a). With the increase of impact energy, the local deformation of the bottom face sheet under the impact point becomes larger and the plastic hinge lines were formed at other three boundaries, as shown in Fig. 12(b)-(d). The plastic hinge lines at the boundary near the impact position were also found, as show in Fig. 13(a). The local deformation of the bottom face sheet under the impact point becomes larger with the increase of impact energy, and the plastic hinge lines at the boundary near the impact position were evident. Also, no obvious deformation was observed at the two boundary areas far away from the impact position, as shown in Fig. 13(b)-(d). Finally, the bottom face sheets of the sandwich plates are perforated, as shown in Fig. 11(d), 12(d) and 13(d).

\subsection{Dynamic response}

Fig. 14 shows impact force-displacement curves of sandwich plates at impact positions P1, P2 and P3. It is seen that the impact force-displacement curve of the sandwich plate increases with the similar slope under different impact energy at the same impact position. With the increase of impact energy, all the peak impact force, the maximum deflection and the permanent deflection after unloading increase. The impact force fluctuates at the initial rising stage, since the honeycomb core material is compressed under the hammer head. When the compression of the core material attains densification, the fluctuation of the impact force-displacement curve is weakened. When the impact position is close to the boundary, the above fluctuations are decreased by the boundary constraints.

Fig. 15 shows impact force-displacement curves of sandwich plates at different positions under impact energy $E_{\text {inp }}=91 J$. The three curves have the similar slopes at the initial stage. However, with increasing the deflections, the slopes of response curves increase and the peak values of impact loading increase from impact positions P1 to P3, while the permanent deflections after unloading decrease. It is possible that the boundary constraint have gradually increasing effects on dynamic response from impact positions P1 to P3.

Fig. 16(a) and (b) show the maximum impact force versus impact position and maximum permanent deflection versus impact position of sandwich plates, respectively. For the low impact energy, the impact positions have small effect on the peak impact force and the permanent deflections of bottom face sheet, while for the high impact energy, the impact positions have significant effects. The peak impact forces increase from impact positions $\mathrm{P} 1$ to $\mathrm{P} 3$, while the permanent deflections decline. It may be the reason that the closer the impact position is to the boundary, the bigger the boundary effect is.

Analytical solutions for dynamic response of fully clamped sandwich plates are presented in Appendix A. Fig. 17(a) and (b) show comparisons between analytical predictions and experimental results for permanent deflections and peak impact forces. The analytical solutions based on the circumscribing yield locus underestimate the experimental results for permanent deflections, while the analytical solutions 


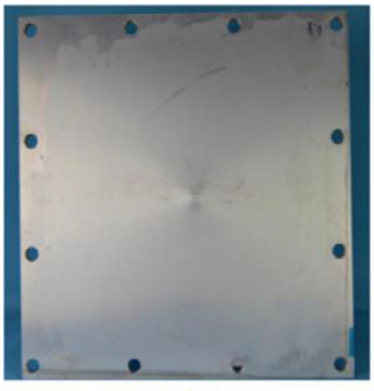

EXP

(a)

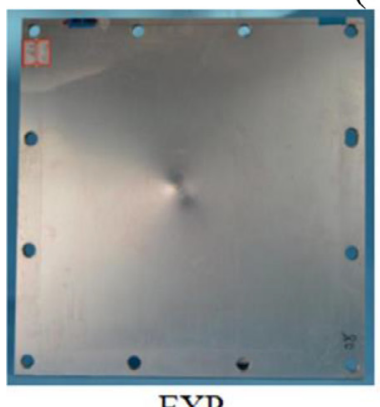

EXP

(b)

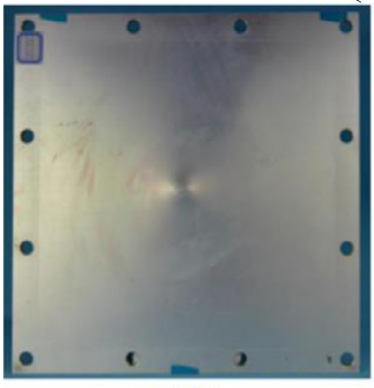

EXP

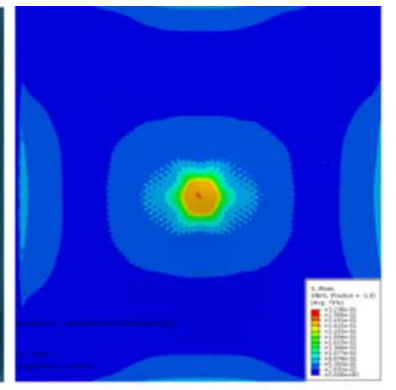

FE

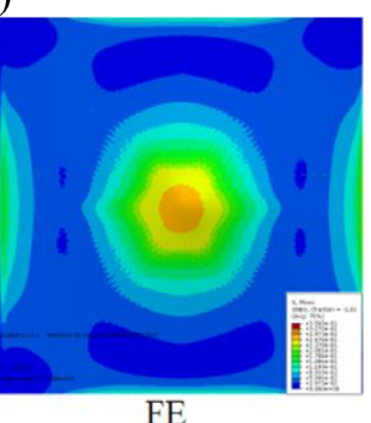

FE

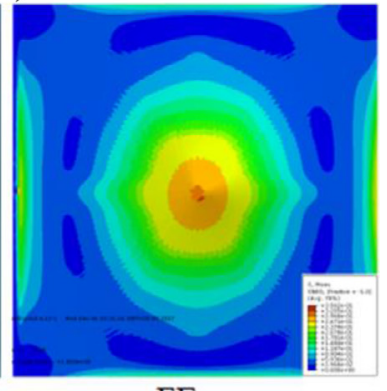

FE

(c)

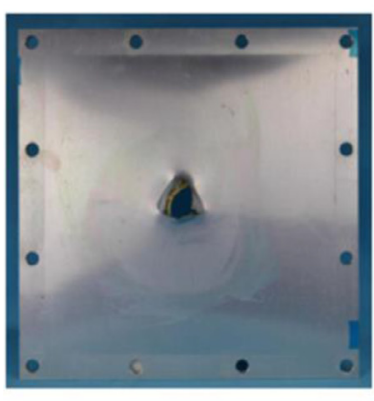

EXP

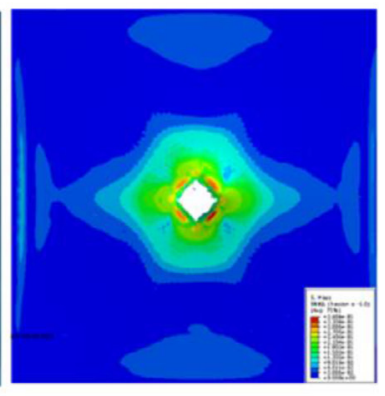

FE (d)

Fig. 11. Deformation and failure modes of the bottom face sheets of sandwich plates at impact position P1. (a) $V_{0}=1.5 \mathrm{~m} / \mathrm{s}, E_{\text {inp }}=39 \mathrm{~J}$, (b) $V_{0}=2.3 \mathrm{~m} / \mathrm{s}$, $E_{\text {inp }}=91 \mathrm{~J}$, (c) $V_{0}=2.5 \mathrm{~m} / \mathrm{s}, E_{\text {inp }}=108 \mathrm{~J}$ and (d) $V_{0}=4 \mathrm{~m} / \mathrm{s}, E_{\text {inp }}=276 \mathrm{~J}$.

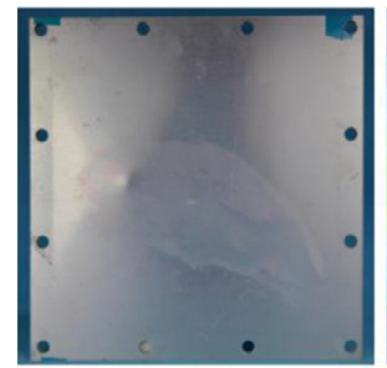

EXP

(a)

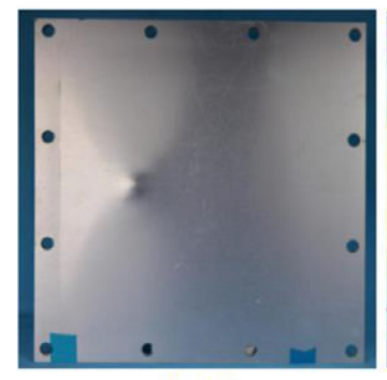

EXP

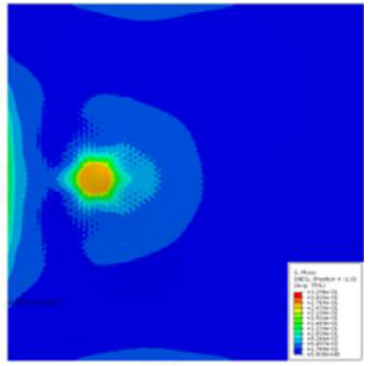

FE

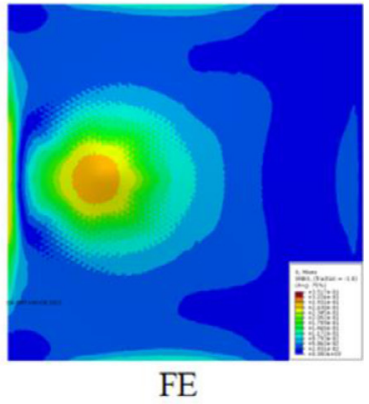

(b)

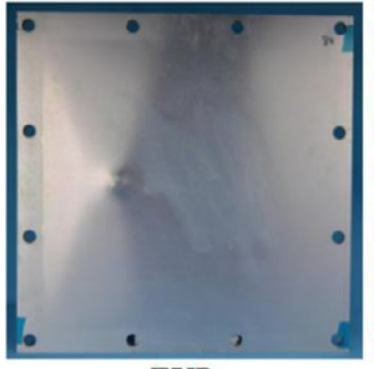

EXP

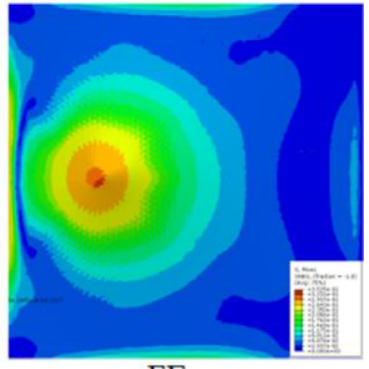

FE (c)

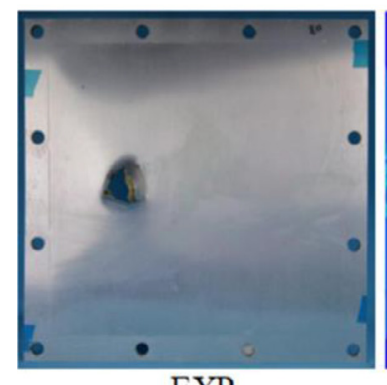

EXP

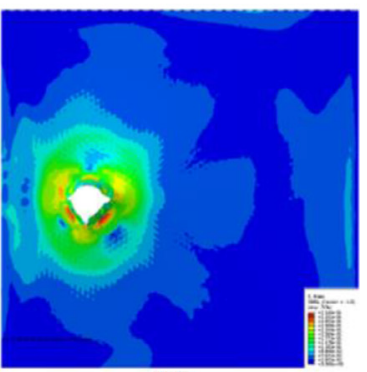

FE (d)

Fig. 12. The deformation and failure modes of the bottom face sheets of sandwich plates at impact position P2. (a) $V_{0}=1.5 \mathrm{~m} / \mathrm{s}, E_{\text {inp }}=39 \mathrm{~J}$, (b) $V_{0}=2.0 \mathrm{~m} / \mathrm{s}, E_{\text {inp }}=69 \mathrm{~J}$, (c) $V_{0}=2.3 \mathrm{~m} / \mathrm{s}, E_{\text {inp }}=91 \mathrm{~J}$ and (d) $V_{0}=4 \mathrm{~m} / \mathrm{s}$, $E_{\text {inp }}=276 J$. 


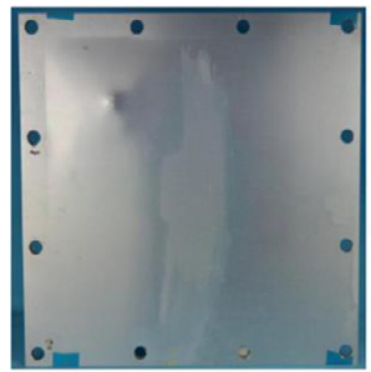

EXP

(a)

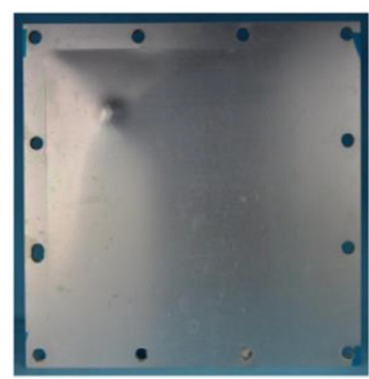

EXP

(b)

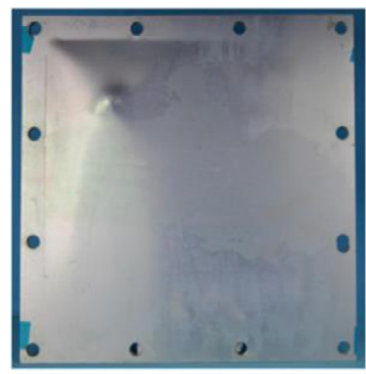

EXP

(c)
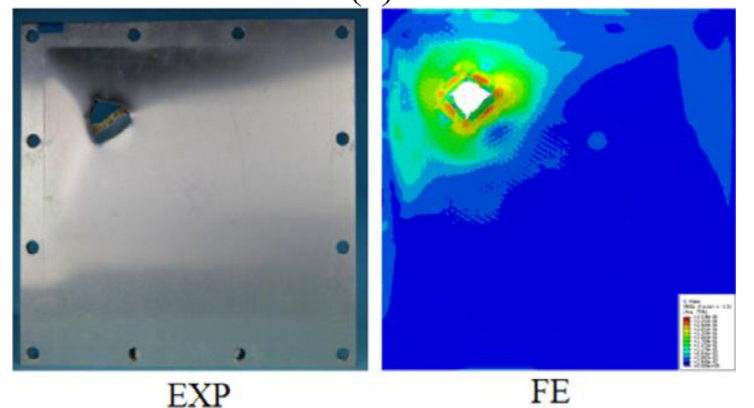

(d)

Fig. 13. Deformation and failure modes of the bottom face sheets of sandwich plates at impact position P1. (a) $V_{0}=1.5 \mathrm{~m} / \mathrm{s}, E_{\text {inp }}=39 \mathrm{~J}$, (b) $V_{0}=2.3 \mathrm{~m} / \mathrm{s}, E_{\text {inp }}=91 \mathrm{~J}$, (c) $V_{0}=2.5 \mathrm{~m} / \mathrm{s}, E_{\text {inp }}=108 \mathrm{~J}$ and (d) $V_{0}=4 \mathrm{~m} / \mathrm{s}$, $E_{\text {inp }}=276 \mathrm{~J}$

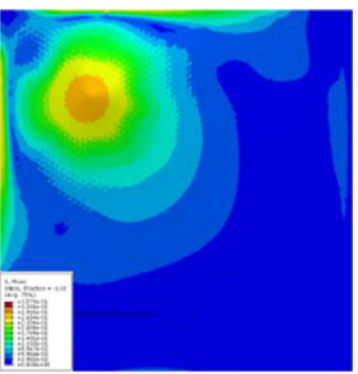

FE

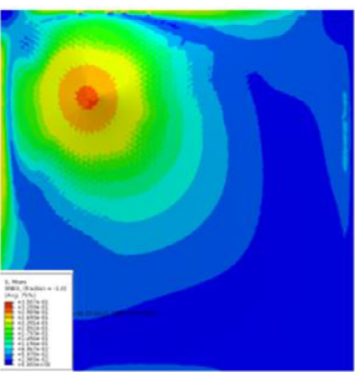

FE

FE

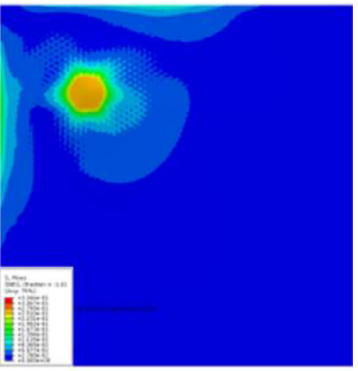

FE 


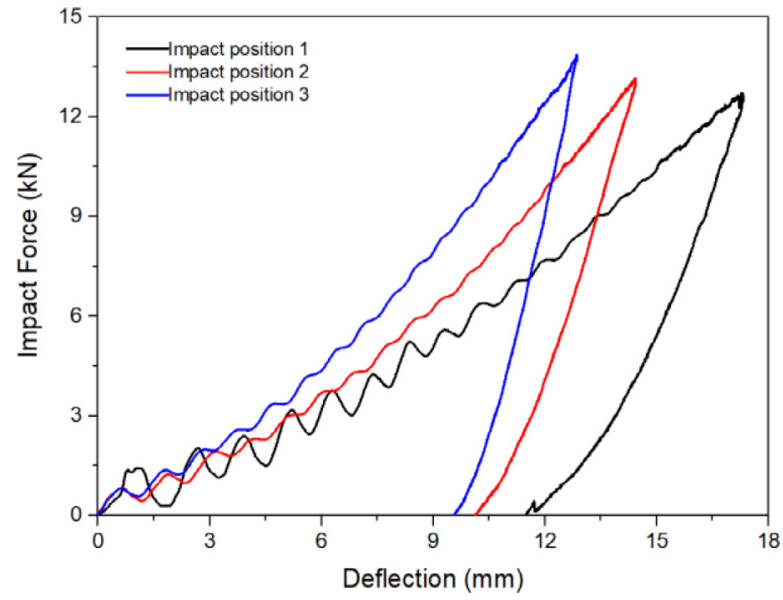

Fig. 15. Impact force-displacement curves at different impact positions $\left(E_{\text {inp }}=91 J\right)$.

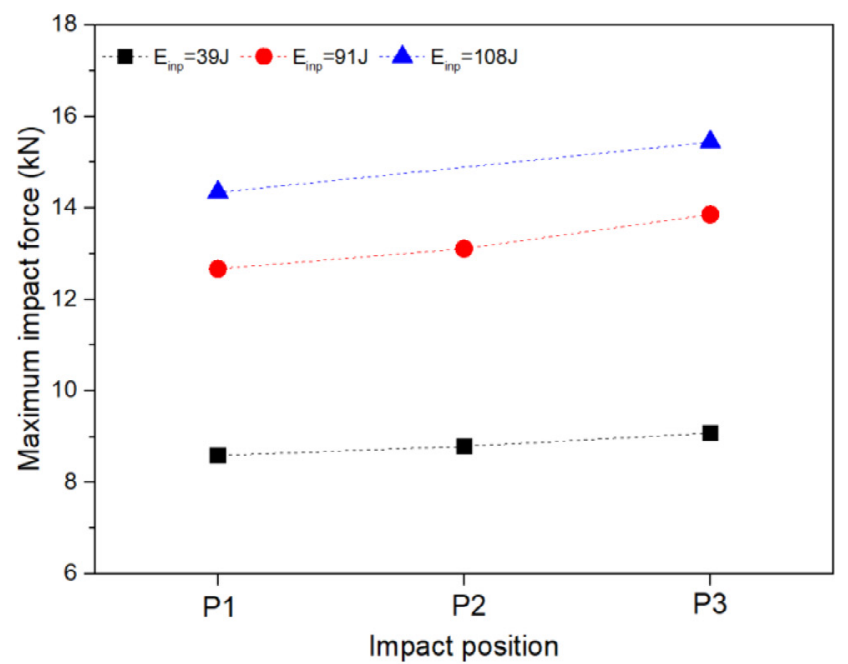

(a)

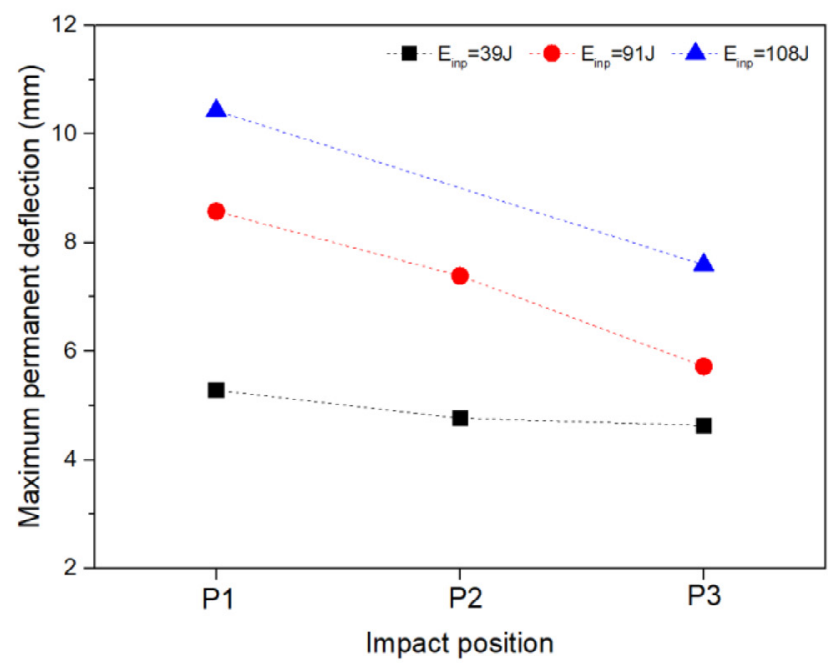

(b)

Fig. 16. (a) Maximum impact force versus impact position of sandwich plates, and (b) maximum permanent deflection versus impact position of sandwich plates.

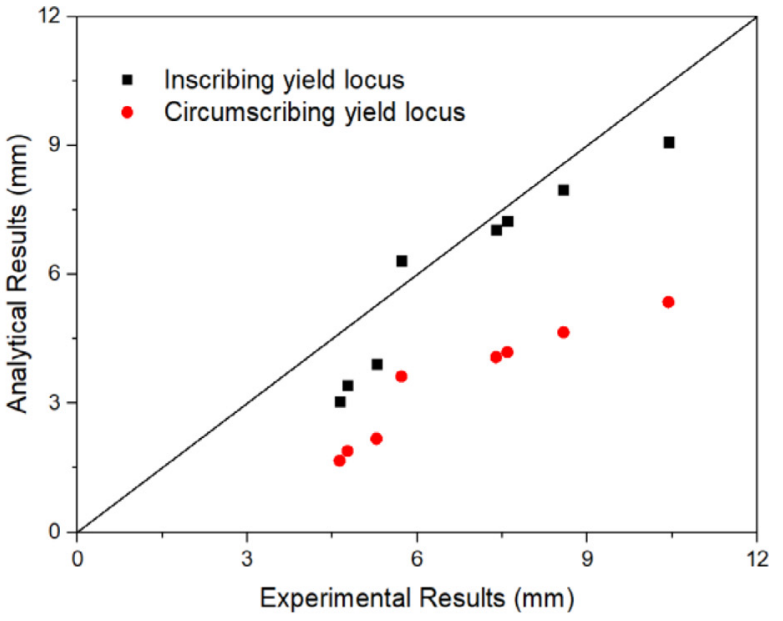

(a)

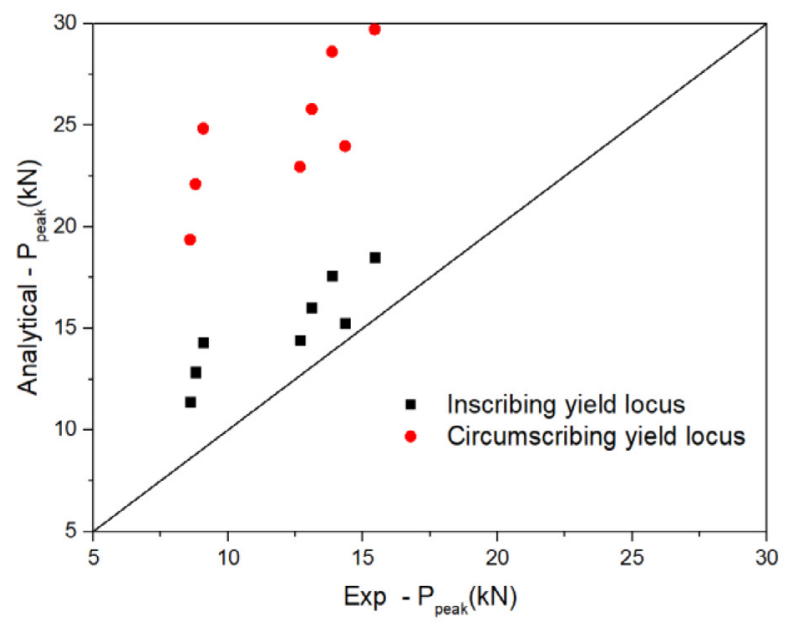

(b)

Fig. 17. Comparison between analytical and experimental results for (a) maximum deflection and (b) maximum peak impact force of sandwich plates.

based on the circumscribing yield locus overestimate the experimental results for peak impact forces. It is seen that the analytical predications based on the inscribing yield locus capture the experimental results reasonably.

\section{Concluding remarks}

Structural impact damage of the fully clamped metal honeycomb sandwich plates under low-velocity impact was investigated experimentally, numerically and theoretically. The failure modes, permanent deflections and impact forces have been measured and the measured dynamic response are compared with the finite element simulations. It is found that the impact position affects the deformation failure mode of sandwich plates. With the change of the impact position, the deformation areas of the top and bottom face sheets of the sandwich plates and the distribution of the plastic hinge lines change obviously due to effect of the boundary condition. The finite element simulations are in good agreement with the observed experimental response. Analytical solutions for the maximum permanent deflections and peak impact force are derived and capture the experimental results with reasonable accuracy. The observed response and finite element simulations reveal that the stiffness of sandwich plate changes in 
the process of dynamic response. Furthermore, it is shown that the impact resistance of sandwich plate decreases from the central position to the non-central positions.

\section{Declaration of Competing Interest}

The authors declare that they have no known competing financial interests or personal relationships that could have appeared to influence the work reported in this paper.

\section{Acknowledgments}

The authors are grateful for their financial support through NSFC (11972281 and 11872291), Opening Project of Science and Technology on Transient Impact Laboratory (614260601010117), Opening project of State Key Laboratory of Explosion Science and Technology (Beijing Institute of Technology, KFJJ18-07M, KFJJ19-15M), Natural Science Basic Research Plan in Shaanxi Province of China (2020JM034), Opening fund of State Key Laboratory of Nonlinear Mechanics, Opening project of State Key Laboratory of Mechanics and Control of Mechanical Structures (Nanjing University of Aeronautics and Astronautics, MCMS-E-0219Y02), and China Postdoctoral Science Foundation funded project (2018M643621).

\section{Data availability}

The data used to support the findings of this study are available from the corresponding author upon request.

\section{Appendix A. Analytical solutions for dynamic response of fully clamped sandwich plates}

Qin et al. [6] obtained the dynamic response solution of large deflection and the upper and lower bounds of metal square sandwich plate under the low-velocity impact. The deflections of the sandwich plate versus response time at the impact point are given by $[6,18]$

$W_{0}(t)=\frac{G V_{0} \sin (\alpha t)}{\left(G+4 \mu L^{2} / 3\right) \alpha}+\frac{\beta^{2}}{\alpha^{2}} \cos (\alpha t)-\frac{\beta^{2}}{\alpha^{2}}$

and

$W_{0}(t)=\frac{G V_{0} \sin (\sqrt{\vartheta} \alpha t)}{\left(G+4 \mu L^{2} / 3\right) \sqrt{\vartheta} \alpha}+\frac{\beta^{2}}{\alpha^{2}} \cos (\sqrt{\vartheta} \alpha t)-\frac{\beta^{2}}{\alpha^{2}}$

where

$\alpha=\sqrt{\frac{\zeta}{2} \frac{\sigma_{c} c+2 \sigma_{f} h}{G+2 \mu L^{2} / 3}}$

$\beta=\sqrt{\frac{\zeta}{2} \frac{\sigma_{c} c^{2}+4 \sigma_{f} h(c+h)}{G+2 \mu L^{2} / 3}}$

$\vartheta=\left\{\begin{array}{l}\frac{\sqrt{1+4 k_{0}}-1}{2 k_{0}}, \frac{8 h}{c}\left(1+\frac{h}{c}\right)-\frac{\sigma_{c}^{2}}{\sigma_{f}^{2}} \leqslant 0 \\ \frac{\sqrt{k_{1}^{2}+4 k_{2}}-k_{1}}{2}, \frac{8 h}{c}\left(1+\frac{h}{c}\right)-\frac{\sigma_{c}^{2}}{\sigma_{f}^{2}}>0\end{array}\right.$

for the circumscribing and inscribing yield loci, where $\sigma_{f}$ and $\sigma_{c}$ are yield strengths of the face sheet and the foam, $L$ is the length of the sandwich plate, $c$ is the height of the core, $h$ is the thickness of the face sheet, $G$ is the mass of the striker, $\mu\left(=\rho_{c} c+2 \rho_{f} h\right)$ is the mass per unit area, $\rho_{f}$ and $\rho_{c}$ are densities of the face sheet and core, $t$ is response time, $k_{0}=\frac{\left(\frac{\sigma_{c}}{\sigma_{f}}+\frac{2 h}{c}\right)^{2}}{\frac{\sigma_{c}}{\sigma_{f}}\left[\frac{4 h}{c}\left(1+\frac{h}{c}\right)+\frac{\sigma_{c}}{\sigma_{f}}\right]}, k_{1}=1+\frac{\left(1-\frac{\sigma_{c}}{\sigma_{f}}\right)\left(\frac{3 \sigma_{c}}{\sigma_{f}}+\frac{8 h}{c}\right)}{\left(\frac{\sigma_{c}}{\sigma_{f}}+\frac{2 h}{c}\right)^{2}}$ and $k_{2}=1+\frac{2\left(1-\frac{\sigma_{c}}{\sigma_{f}}\right)}{\frac{\sigma_{c}}{\sigma_{f}}+\frac{2 h}{c}}$.

The accelerated speed of the striker is
$\ddot{W}_{0}(t)=\frac{d^{2} W_{0}(t)}{d t^{2}}=\frac{G V_{0}^{2} \sqrt{\vartheta} \alpha \sin (\sqrt{\vartheta} \alpha t)}{G+4 \mu L^{2} / 3}+\beta^{2} \vartheta \cos (\sqrt{\vartheta} \alpha t)$

or

$\ddot{W}_{0}(t)=\vartheta \alpha^{2} \cdot W_{0}(t)+\beta^{2} \vartheta$

The reaction force between the hammer head and the sandwich plate is

$F(t)=G \cdot \ddot{W}_{0}(t)=G \vartheta \alpha^{2} \cdot W_{0}(t)+G \vartheta \beta^{2}$

Zhang et al. [19] obtained the bounds for the reaction force between the striker and the sandwich plate of the multilayer sandwich plate for the inscribing locus.

For simplify, the following parameters are defined by

$K_{1}=G \vartheta \alpha^{2}=\frac{G \zeta \vartheta}{2} \cdot \frac{\sigma_{c} c+2 \sigma_{f} h}{G+2 \mu L^{2} / 3}, K_{2}=G \vartheta \beta^{2}=\frac{G \zeta \vartheta}{2} \cdot \frac{\sigma_{c} c^{2}+4 \sigma_{f} h(c+h)}{G+2 \mu L^{2} / 3}$

According to the law of conservation of energy, we have

$\int_{0}^{W_{0-\max }} F d W_{0}=\frac{1}{2} K_{1} \cdot W_{0-\max }^{2}+K_{2} \cdot W_{0-\max }=\frac{1}{2} G \cdot V_{0}^{2}$

The expressions of the maximum deflection and the maximum impact peak force of sandwich plate at different impact positions are given by

$W_{0-\max }=\sqrt{\left(K_{2} / K_{1}\right)^{2}+G V_{0}^{2} / K_{1}}-K_{2} / K_{1}$

and

$F_{\max }=\sqrt{K_{2}^{2}+K_{1} G V_{0}^{2}}$

for the inscribing yield locus, respectively.

Similarly, based on the circumscribing yield locus, the expressions of the maximum deflection and the maximum impact peak force of sandwich plate at different impact positions can be expressed as

$W_{0-\max }=\sqrt{\left(K^{\prime}{ }_{2} / K^{\prime}{ }_{1}\right)^{2}+G V_{0}^{2} / K^{\prime}}{ }_{1}-K_{2}^{\prime} / K_{1}^{\prime}$

and

$F_{\max }=\sqrt{K_{2}^{\prime 2}+K_{1}^{\prime} G V_{0}^{2}}$

where

$$
K_{1}^{\prime}=G \alpha^{2}=\frac{G \zeta}{2} \cdot \frac{\sigma_{c} c+2 \sigma_{f} h}{G+2 \mu L^{2} / 3} \text { and } K_{2}^{\prime}=G \beta^{2}=\frac{G \zeta}{2} \cdot \frac{\sigma_{c} c^{2}+4 \sigma_{f} h(c+h)}{G+2 \mu L^{2} / 3} .
$$

\section{References}

[1] Foo CC, Chai GB, Seah LK. A model to predict low-velocity impact response and damage in sandwich composites. Compos Sci Technol 2008;68:1348-56.

[2] Plagianakos TS, Papadopoulos EG. Low-energy impact response of composite and sandwich composite plates with piezoelectric sensory layers. Int J Solids Struct 2014;51:2713-27.

[3] Fard KM, Khalili SMR, Forooghy SH, Hosseini M. Low velocity transverse impact response of a composite sandwich plate subjected to a rigid blunted cylindrical impactor. Compos B 2014;63:111-22.

[4] Mohammadi Y, Khalili SMR, Fard KM. Low velocity impact analysis of sandwich plates with functionally graded face sheets. Mech Adv Mater Struct 2016;23 (4):363-74.

[5] Arachchige B, Ghasemnejad H. Effect of variable core stiffness on the impact response of curved sandwich plates. Compos Struct 2018;200:565-78.

[6] Qin QH, Zheng XY, Zhang JX, Yuan C, Wang TJ. Dynamic response of square sandwich plates with a metal foam core subjected to low-velocity impact. Int $\mathrm{J}$ Impact Eng 2018;111:222-35.

[7] Herup EJ, Palazotto AN. Low-velocity impact damage initiation in Graphite/ Epoxy/Nomex honeycomb-sandwich plates. Compos Sci Technol 1997;57:1581-98.

[8] Crupi V, Montanini R. Aluminium foam sandwiches collapse modes under static and dynamic three-point bending. Int J Impact Eng 2007;34:509-21.

[9] Yu J, Wang E, Li J, Zheng Z. Static and low-velocity impact behavior of sandwich beams with closed-cell aluminum-foam core in three-point bending. Int $\mathrm{J}$ Impact Eng 2008;35:885-94.

[10] Rajaneesh A, Sridhar I, Rajendran S. Impact modeling of foam cored sandwich plates with ductile or brittle faceplates. Compos Struct 2012;94:1745-54. 
[11] Ivañez I, Moure MM, Garcia-Castillo SK, Sanchez-Saez S. The oblique impact response of composite sandwich plates. Compos Struct 2015;133:1127-36.

[12] Kurşun A, Şenel M, Enginsoy HM, Bayraktar E. Effect of impactor shapes on the low velocity impact damage of sandwich composite plate: Experimental study and modelling. Compos B 2016;86:143-51.

[13] Abo Sabah SH, Kueh ABH. Finite element modeling of laminated composite plates with locally delaminated interface subjected to impact loading. The Scientific World Journal 2014;2014:954070.

[14] Liu PF, Li XK, Li ZB. Finite element analysis of dynamic mechanical responses of aluminum honeycomb sandwich structures under low-velocity impact. J Fail Anal Prev 2017;17:1202-7.
[15] Chen Y, Hou SJ, Fu KK, Han X, Ye L. Low-velocity impact response of composite sandwich structures: modelling and experiment. Compos Struct 2017;168:322-34.

[16] Park H. Investigation on low velocity impact behavior of sandwich composite and monolithic laminate plates using FEM analysis. Compos Struct 2019;220:842-6.

[17] Johnson GR, Cook WH. Fracture characteristics of three metals subjected to various strains, strain rates, temperatures and pressures. Eng Fract Mech 1985;21:31-48.

[18] Qin QH, Wang TJ. Low-velocity heavy-mass impact response of slender metal foam core sandwich beam. Compos Struct 2011;93:1526-37.

[19] Zhang JX, Liu K, Ye Y, Qin QH. Low-velocity impact of rectangular multilayer sandwich plates. Thin-Walled Struct 2019;141:308-18. 